\title{
TRABALHO INFANTIL: PERSISTÊNCIA INTERGERACIONAL E DECOMPOSIÇÃO DA INCIDÊNCIA ENTRE 1992 E 2004 NO BRASIL RURAL E URBANO*
}

\author{
Juliana Maria Aquino ${ }^{* *}$
}

Maurício Machado Fernandes ${ }^{* *}$

Elaine Toldo Pazello

Luiz Guilherme Scorzafave $e^{* * * *}$

RESUMO O objetivo deste artigo é diagnosticar a existência da transmissão intergeracional do trabalho infantil, utilizando modelos Probit para as regiões rurais e urbanas do Brasil. Além disso, decompomos a variação do trabalho infantil entre 1992 e 2004 para investigar os fatores determinantes na queda do trabalho infantil no período. Os resultados da pesquisa mostram que o fato de os pais terem sido trabalhadores infantis tem um efeito positivo e significante sobre a probabilidade de seus filhos trabalharem, tanto nas áreas urbanas quanto rurais do Brasil. Entretanto, a magnitude desse impacto é muito mais acentuada na zona rural. Além disso, um dos fatores principais para a queda da incidência do trabalho infantil no período foi o aumento da escolaridade dos pais e mães.

\footnotetext{
* Artigo recebido em 8 de maio de 2008 e aprovado em 15 de setembro de 2009.

** Doutoranda em Economia pela ESALQ/USP e mestre em Economia Aplicada pela Fearp/USP, e-mail: jmaquino@usp.br

*** Doutorando em Economia pelo Departamento de Economia da PUC-Rio e mestre em Economia Aplicada pela Fearp/USP, e-mail: mauriciomfernandes@yahoo.com

**** Professora Doutora da Faculdade de Economia, Administração e Contabilidade da USP/RP, e-mail: epazello@usp.br

***** Professor Doutor da Faculdade de Economia, Administração e Contabilidade da USP/RP, e-mail: scorza@usp.br
} 
Palavras-chave: trabalho infantil; persistência intergeracional; Brasil rural; decomposição.

Código JEL: J22; J24

\title{
CHILD LABOR:
}

\section{INTERGENERATIONAL PERSISTENCE AND INCIDENCE DECOMPOSITION IN RURAL AND URBAN BRAZIL BETWEEN 1992 AND 2004}

\begin{abstract}
The aim of this paper is to investigate if there is child labor intergenerational persistence, using separating Probit models for urban and rural areas of Brazil. Moreover, we decompose the child labor variation between 1992 and 2004 in order to understand the factors responsible for child labor decrease in the period. The results show that if the parents were child workers in the past, this increases the probability of child labor of their children and this is true in Brazilian urban and rural areas. However, the impact is stronger in rural areas. Moreover, an important factor explaining the fall of child labor in the period was the increase of parents' schooling.
\end{abstract}

Key words: child labor; intergenerational persistence; rural Brazil; decomposition 


\section{INTRODUÇÃO}

O trabalho infantil é um fenômeno de grande proporção e sua incidência se dá principalmente nos países em desenvolvimento. Dados de 2002 da Organização Internacional do Trabalho (OIT) evidenciaram 352 milhões de crianças e adolescentes com idade entre 5 e 17 anos participando do mercado de trabalho em todo o mundo. Entre esses, aproximadamente $70 \%$ trabalham em atividades consideradas exploradoras e cerca de $20 \%$ têm idade inferior a 10 anos.

A maior parte dos trabalhadores infantis vive no Continente Asiático (cerca de 60\%); os demais se distribuem entre a África (32\%), América Latina $(7 \%)$ e Oceania $(0,2 \%)$. Em termos relativos, no entanto, a África aparece em primeiro lugar, seguido da Ásia, América Latina e Oceania.

No Brasil, ao longo da década de 1990, segundo dados do IBGE, houve uma queda acentuada na quantidade de crianças trabalhadoras: em 1992, 9 milhões de crianças entre 10 e 17 anos compunham a força de trabalho brasileira; em 1999, esse número caiu para 7,3 milhões. Essa redução continuou nos anos 2000, e em 2004 havia 5 milhões de crianças nessa mesma faixa etária trabalhando, e destas, 34\% tinham entre 10 e 14 anos. Assim, embora tenha ocorrido importante redução, os números relativos ao trabalho infantil continuam expressivos, o que explica o fato de o trabalho infantil continuar a ser alvo de esforços governamentais e de pesquisas com o objetivo de reduzir sua incidência.

Com relação às pesquisas, a literatura do trabalho infantil geralmente é composta por estudos que buscam identificar seus determinantes, suas consequências e/ou avaliam políticas e programas sociais que visam à sua eliminação. Dentre os estudos que procuram identificar as principais causas do trabalho infantil, Kassouf (2001), entre outros, constatou que a renda familiar apresenta impacto negativo sobre a incidência do trabalho infantil. No entanto, Barros, Mendonça e Velazco (1994) mostraram que a renda não é a principal causa desse tipo de trabalho no Brasil. Ser menino, ter cor parda e pertencer a famílias numerosas e chefiadas por mulheres são características que impactam positivamente a probabilidade de a criança trabalhar (Cavalieri, 2000). Por outro lado, residir em áreas urbanas e ter pais mais instruídos reduz as chances de a criança ser um trabalhador infantil (Ferro, 2003). 
Em relação à atividade econômica dos pais, Schwartzman e Schwartzman (2004) constatou que fazer parte de famílias cujos pais trabalham por conta própria aumenta a probabilidade de a criança trabalhar. Além disso, Emerson e Souza (2003) observaram fortes evidências da ligação entre o trabalho infantil dos pais e o dos filhos no Brasil.

Outros estudos compreendidos pela literatura do trabalho infantil vão além da identificação de seus determinantes e procuram estabelecer as possíveis consequências atribuídas às crianças que iniciaram suas atividades ainda na infância. Kassouf (1999) observou que, quanto mais tarde um indivíduo ingressa no mercado de trabalho, menor é a chance de ele reportar estar doente. Cavalieri (2000) identificou efeitos restritivos do trabalho infantil sobre a escolaridade da criança e Emerson e Souza (2002) encontraram evidências da relação negativa entre trabalho precoce e rendimento futuro.

Uma terceira linha de estudos que abrange o tema trabalho infantil procura avaliar o impacto de programas e políticas sociais sobre a ocorrência desse tipo de trabalho. Soares e Pianto (2003) avaliaram o Programa de Erradicação do Trabalho Infantil (Peti), e os resultados apontaram que o programa foi eficiente na redução desse tipo de trabalho, sendo o efeito mais intenso em pequenos municípios. O impacto do programa Bolsa Escola foi avaliado por Ferro (2003), e os resultados indicaram que o programa surte efeito sobre a redução do número de horas mensais de trabalho das crianças - cada bolsa adicional diminui a jornada das crianças que trabalham em duas horas na área urbana e três horas na área rural. Quanto à decisão de trabalhar ou não, os resultados não foram conclusivos.

O presente estudo procura, a partir dos dados da Pesquisa Nacional por Amostras de Domicílios (Pnad) para os anos 1992 e 2004, identificar a persistência intergeracional do trabalho infantil analisando separadamente as áreas rurais e urbanas do Brasil. Essa separação é importante, pois os determinantes do trabalho infantil são diferentes nas duas regiões.

Adicionalmente, iremos investigar quais fatores mais contribuíram para a redução do trabalho infantil no Brasil entre 1992 e 2004, por meio da análise da decomposição do trabalho infantil com uma técnica similar à decomposição de Oaxaca-Blinder. Assim, verificaremos, por exemplo, se é uma menor persistência intergeracional do trabalho infantil a principal responsável pela sua redução entre 1992 e 2004. 
O artigo está organizado em cinco seções, além desta introdução. A primeira seção apresenta o modelo teórico a ser utilizado. Na segunda seção discute-se a metodologia adotada na investigação empírica do artigo. $\mathrm{Na}$ terceira seção, é descrita a base de dados e realizada a análise descritiva. $\mathrm{Na}$ quarta seção são apresentados os resultados obtidos. Finalmente, na quinta seção, apresentam-se as principais conclusões.

\section{REFERENCIAL TEÓRICO}

Na presente seção, será descrito de forma sucinta o modelo teórico desenvolvido por Emerson e Souza (2003) para explicar a persistência intergeracional do trabalho infantil. Esse modelo sobre a decisão da oferta de trabalho infantil nas famílias irá nortear a realização da investigação empírica e facilitar a interpretação dos resultados obtidos. Entretanto, vale ressaltar que não se pretende realizar a verificação empírica do modelo em questão.

No modelo, as famílias são compostas por dois indivíduos, um adulto e uma criança, em cada período do tempo. Cada um dos agentes vive por dois períodos, de tal forma que uma criança em um período qualquer torna-se um adulto no período seguinte e passa a ter a obrigação de criar outra criança, seu filho. Essas características básicas apresentadas permitem a classificação do modelo como de gerações sobrepostas em tempo discreto, assim como o modelo Diamond apresentado por Romer (2006).

A decisão quanto à oferta de trabalho infantil na família em cada período de tempo cabe ao adulto, que, por hipótese, é um indivíduo altruísta, ou seja, preocupa-se com o bem-estar do seu filho, a criança. Além disso, dois são os fatores que definem o grau de satisfação (preferências) do indivíduo adulto em cada período do tempo: o consumo presente $\left(c_{t}\right)$ de sua família e o oferecimento de educação ao seu filho, ou seja, o nível de capital humano $\left(h_{t+1}\right)$ que essa criança poderá acumular. Portanto, o chefe da família (adulto) opta por fazer seu filho trabalhar desde que a contribuição do trabalho da criança para o consumo presente da família supere os benefícios do acréscimo de consumo futuro que a família poderia obter caso o seu filho continuasse os estudos e obtivesse uma taxa de salário e renda superiores no período seguinte. 
Dessa forma, a função de utilidade do adulto é representada por:

$$
U_{t}=U\left(c_{t}, h_{t+1}\right)
$$

e a restrição orçamentária da família será dada pela igualdade entre o consumo presente e o total de recursos disponíveis:

$$
c_{t}=W_{t}
$$

O total de recursos disponíveis à família é o somatório dos rendimentos do adulto e da criança:

$$
W_{t}=w_{t}^{c}+w_{t}^{a}
$$

O rendimento do adulto é igual ao total de capital humano acumulado por ele quando criança (uma unidade de tempo vezes a taxa de salário do adulto), e o rendimento da criança é a unidade (uma unidade de tempo sendo remunerada por uma unidade monetária) menos a fração do seu tempo dedicado ao estudo $\left(e_{t}\right)$ :

$$
\begin{aligned}
& w_{t}^{A}=h_{t} \\
& w_{t}^{c}=1-e_{t}
\end{aligned}
$$

No entanto, antes da adentrar o mecanismo mediante o qual se realiza o processo de decisão sobre a oferta de trabalho da criança, é de grande relevância destacar alguns pressupostos adotados por Emerson e Souza (2003) para a construção desse modelo teórico: (i) a taxa de salário dos adultos é unicamente determinada pelo nível de capital humano acumulado pelo indivíduo no período em que este foi criança; (ii) a acumulação de capital humano das crianças é uma função crescente do grau de escolaridade delas; (iii) existe um trade-off entre a acumulação de capital humano pela criança e o trabalho infantil; e (iv) por último, o mercado de capitais é imperfeito, de tal forma que não é possível para as famílias tomarem recursos emprestados para financiar o estudo de seus filhos.

Formalizando a relação entre o capital humano acumulado pela criança e o seu grau de escolaridade, tem-se a seguinte função:

$$
h_{t+1}=f\left(e_{t}\right)
$$


O problema de escolha do agente adulto no presente modelo é definido como a maximização de sua utilidade sujeita às restrições dadas pelas equações (2 a 5), após as manipulações necessárias, ou seja:

$$
\max _{e_{t}} U\left(h_{t}+1-e_{t}, f\left(e_{t}\right)\right)
$$

A escolha ótima de $e_{t}$ será, então, dada por:

$$
e^{*}=g\left(h_{t}\right)
$$

Como é possível observar, a escolha ótima do tempo que a criança dedica à escola depende do capital humano acumulado pelo adulto na família. Substituindo essa solução na equação 5 , determina-se, então, uma equação em diferenças que exprime a dinâmica do processo de acumulação de capital humano adotado pelas famílias: o nível de capital humano acumulado pela criança em $t+1$ depende do nível de capital humano acumulado pelo adulto em $t$.

$$
h_{t+1}=f\left[g\left(h_{t}\right)\right] \cong \phi\left(h_{t}\right)
$$

Desde que as funções $f($.$) e g($.) satisfaçam algumas restrições (por exemplo, derivadas primeiras positivas), a equação que determina a dinâmica de acumulação de capital humano pode apresentar vários equilíbrios de estado estacionário, sendo alguns estáveis e outros instáveis.

Supomos a existência de dois equilíbrios estáveis - criança apenas trabalha (não estuda) e criança apenas estuda (não trabalha) —, além de um equilíbrio instável intermediário entre os dois citados anteriormente. O equilíbrio instável é, na verdade, um ponto crítico da trajetória de acumulação de capital humano das famílias. Ou seja, o modelo teórico implica a existência de uma "armadilha" intergeracional na qual, se a família inicia em um ponto inferior ao ponto crítico na trajetória de acumulação de capital humano, nas próximas gerações o patamar de capital humano decrescerá até atingir o equilíbrio estável inferior, em que as crianças apenas trabalham e não estudam. O inverso ocorre caso a família inicie em um ponto da trajetória acima do ponto crítico, culminando no equilíbrio superior: crianças apenas estudam e não trabalham. 
De acordo com essa interpretação, a "armadilha" intergeracional consiste em uma tendência irreversível de algumas famílias caminharem para o equilíbrio superior, enquanto outras para o inferior, consistindo em um círculo vicioso incapaz de ser rompido.

\section{METODOLOGIA}

\subsection{Modelo estimado}

Em virtude da natureza dicotômica da variável dependente, foram utilizados, neste estudo, modelos logit para diagnosticar a existência da transmissão intergeracional do trabalho infantil. De acordo com a equação 9, a probabilidade de a criança $i$ participar do mercado de trabalho está associada tanto ao fato de os pais terem sido trabalhadores infantis $\left(P I_{i}\right)$ como às suas próprias características $\left(C_{i}\right)$ e de sua família $\left(F_{i}\right)$.

$$
Y_{i}=\beta_{0}+\beta_{1} P I_{i}+\beta_{2} C_{i}+\beta_{3} F_{i}+u_{i}
$$

onde:

- $Y_{i}$ (variável dependente): dummy que identifica se a criança participa do mercado de trabalho;

- $P I_{i}$ (persistência intergeracional do trabalho infantil): dummy que capta se os pais trabalharam quando crianças;

- $C_{i}$ (características da criança): idade, dummy de gênero e dummy que identifica o número de irmãos e irmãs por faixas de idade;

- $F_{i}$ (características dos pais): idade, escolaridade e dummy para captar a situação de desemprego;

- $u_{i}$ : termo de erro.

\subsection{Técnica de decomposição}

Neste item, discutimos a técnica de decomposição da evolução do trabalho infantil no tempo. Para compreendermos quais fatores foram responsáveis pela redução desse tipo de trabalho ao longo dos anos, iremos adotar a técnica de decomposição apresentada por Yun (2005). Tal técnica, semelhante à de Oaxaca-Blinder, identifica uma parcela da variação do trabalho infantil como sendo devida à mudança nos valores dos regressores que determinam 
o trabalho infantil e outra que capta alteração nos coeficientes associados a esses regressores. Assim, por exemplo, o trabalho infantil pode ter diminuído ou porque a qualificação dos pais cresceu no período (assumindo-se relação inversa entre qualificação dos pais e incidência do trabalho infantil), ou porque a qualificação dos pais passou a impactar de modo mais fraco a incidência do trabalho infantil entre os períodos analisados.

A diferença com relação à decomposição de Oaxaca-Blinder é que a de Yun (2005) leva em consideração o problema da indeterminação dos efeitos dos coeficientes associados a variáveis explicativas, no caso de estas serem variáveis binárias. Em resumo, o problema é que, dependendo dos grupos omitidos na estimação com variáveis dummy, o resultado da decomposição seria diferente. Assim, por exemplo, se incluirmos a variável binária "pai foi trabalhador infantil”, o resultado da contribuição da alteração dos coeficientes para explicar a redução da incidência do trabalho infantil será diferente do que se tivéssemos incluído a dummy "pai não foi trabalhador infantil”. Assim, Yun (2005) propõe calcularmos a média das duas contribuições e assumir esse resultado como sendo a contribuição da alteração do coeficiente associado à variável de trabalho infantil do pai. ${ }^{1}$

\section{DADOS}

Os dados utilizados neste estudo são da Pesquisa Nacional por Amostragem de Domicílios dos anos 1992 e 2004. A Pnad é uma amostra representativa do país (com exceção da área rural da região Norte até 2003). ${ }^{2}$ A amostra é composta por crianças com idade entre 10 e 14 anos cuja condição na família é a de filho ou outro parente. A ideia de incluir as crianças consideradas como "outro parente" é que a Pnad só permite a identificação da relação de parentesco com a pessoa de referência da família. Assim, um enteado da pessoa de referência, mesmo que filho da pessoa classificada como cônjuge na família, é classificado como outro parente da pessoa de referência. Nesse sentido, não estamos distinguindo o tratamento dado a filhos biológicos do dado aos enteados, ou ainda àquelas crianças que moram com avós, tios etc. Assim, uma possível ressalva que pode ser feita com relação a esse fato é que a relação entre pais e filhos biológicos dentro da família pode ser diferente daquela de outras crianças que não os filhos biológicos. O fato de não estar- 
mos considerando essas diferenças pode, a princípio, estar influenciando nossos resultados. ${ }^{3}$ Seguindo o mesmo critério de Emerson e Souza (2003), foram incluídas na amostra somente famílias completas, ou seja, famílias com mãe e pai presentes. Essa restrição se faz necessária para a análise da correlação existente entre o trabalho infantil dos pais e dos filhos. Finalmente, foram excluídas da amostra todas as observações para as quais a diferença entre a idade do pai ou da mãe e a idade do filho mais velho fosse igual ou menor do que 14 anos. Isso foi feito para se ter uma maior probabilidade de que o componente da família identificado como filho fosse de fato filho do casal. Mesmo assim, é possível que não estejamos identificando corretamente se o indíviduo é realmente filho do casal.

Tal como mencionado na Introdução, um dos objetivos do artigo é identificar a persistência intergeracional do trabalho infantil. A criança foi definida como sendo trabalhadora infantil caso tenha exercido alguma atividade remunerada ou não, por qualquer hora positiva, na semana de referência da pesquisa. ${ }^{4}$ Quanto ao status de trabalho infantil dos pais, esses serão considerados como antigos trabalhadores infantis caso tenham iniciado suas atividades laborais antes de completarem 15 anos de idade. ${ }^{5}$

A amostra final, base para os exercícios econométricos do artigo, tem 28.952 observações para 1992, sendo 5.063 (17,49\%) trabalhadores infantis. Já para 2004, há 26.504 observações, sendo, desse total, 2.553 (9,63\%) crianças trabalhadoras.

A tabela 1 apresenta os valores médios e de desvio-padrão para um conjunto de variáveis para as crianças que trabalham e para as que não trabalham. De acordo com os dados da tabela, a maior parte das crianças que trabalham é de meninos e vive na área rural do país. No entanto, não há diferença significativa em termos da escolaridade média das crianças. Por outro lado, os pais (e mães) das crianças que não trabalham são em média mais educados. A porcentagem de pais (e mães) que estão fora do mercado de trabalho $^{6}$ é maior dentre as crianças que não trabalham. Cabe ressaltar aqui a forte queda da inatividade feminina entre 1992 e 2004 em ambos os grupos.

A tabela 2 apresenta a relação existente entre o status de trabalho infantil entre gerações. Inicialmente, destacamos a substancial redução do trabalho infantil (entre 10 e 14 anos), passando de 17,5\% em 1992 para 9,6\% em 2004. Nota-se, ainda, que cerca de $70 \%$ dos pais e $40 \%$ das mães iniciaram suas 
Tabela 1: Características descritivas das variáveis para o Brasil

\begin{tabular}{|c|c|c|c|c|}
\hline & \multicolumn{2}{|c|}{1992} & \multicolumn{2}{|c|}{2004} \\
\hline & $\begin{array}{c}\text { Crianças } \\
\text { que não } \\
\text { trabalham }\end{array}$ & $\begin{array}{c}\text { Crianças } \\
\text { que } \\
\text { trabalham }\end{array}$ & $\begin{array}{c}\text { Crianças } \\
\text { que não } \\
\text { trabalham }\end{array}$ & $\begin{array}{c}\text { Crianças } \\
\text { que } \\
\text { trabalham }\end{array}$ \\
\hline \multicolumn{5}{|l|}{ Características das crianças } \\
\hline \multirow[t]{2}{*}{ Idade } & 11,82 & 12,45 & 11,89 & 12,54 \\
\hline & $(1,39)$ & $(1,35)$ & $(1,41)$ & $(1,35)$ \\
\hline$\%$ de meninas & $52,9 \%$ & $30,3 \%$ & $51,4 \%$ & $30,7 \%$ \\
\hline \% que vive na área urbana & $83,4 \%$ & $45,6 \%$ & $81,8 \%$ & $41,2 \%$ \\
\hline \multirow[t]{2}{*}{ Escolaridade } & 3,10 & 2,51 & 4,09 & 3,98 \\
\hline & $(1,89)$ & $(2,02)$ & $(1,77)$ & $(1,95)$ \\
\hline \multicolumn{5}{|l|}{ Características dos pais } \\
\hline \multirow[t]{2}{*}{ Idade do pai } & 43,60 & 45,22 & 43 & 44,94 \\
\hline & $(9,06)$ & $(9,52)$ & $(9,25)$ & $(9,67)$ \\
\hline \multirow[t]{2}{*}{ Escolaridade do pai } & 4,84 & 2,31 & 5,78 & 3,15 \\
\hline & $(4,40)$ & $(2,77)$ & $(4,42)$ & $(3,37)$ \\
\hline$\%$ pais fora do mercado & $11,9 \%$ & $5,8 \%$ & $12,50 \%$ & $6,20 \%$ \\
\hline \multirow[t]{2}{*}{ Idade da mãe } & 39,32 & 40,39 & 38,9 & 40,3 \\
\hline & $(7,72)$ & $(7,88)$ & $(7,97)$ & $(8,16)$ \\
\hline \multirow[t]{2}{*}{ Escolaridade da mãe } & 4,81 & 2,53 & 6,19 & 3,61 \\
\hline & $(4,17)$ & $(2,79)$ & $(4,35)$ & $(3,41)$ \\
\hline \% mães fora do mercado & $56,2 \%$ & $39,0 \%$ & $47,10 \%$ & $24,50 \%$ \\
\hline $\mathrm{N}^{\circ}$ de observações & 23.879 & 5.063 & 23.951 & 2.553 \\
\hline
\end{tabular}

Desvio-padrão entre parênteses.

Fonte: Pnad (1992, 2004) - Elaboração própria.

Tabela 2: Distribuição de trabalho infantil de acordo com o status de trabalhador infantil do pai e da mãe, Brasil

\begin{tabular}{|c|c|c|c|c|c|}
\hline \multirow[b]{3}{*}{ Criança trabalha } & \multicolumn{4}{|c|}{1992} & \multirow[b]{3}{*}{ Total } \\
\hline & \multicolumn{2}{|c|}{$\begin{array}{l}\text { Pai da criança era } \\
\text { trabalhador infantil }\end{array}$} & \multicolumn{2}{|c|}{$\begin{array}{l}\text { Mãe da criança era } \\
\text { trabalhadora infantil }\end{array}$} & \\
\hline & Não & Sim & Não & Sim & \\
\hline Não & 7.700 & 16.179 & 15.821 & 8.058 & 23.879 \\
\hline$\underline{\operatorname{Sim}}$ & 650 & 4.413 & 1.740 & 3.323 & 5.063 \\
\hline \multirow[t]{3}{*}{ Total } & 8.350 & 20.592 & 17.561 & 11.381 & 28.942 \\
\hline & \multicolumn{4}{|c|}{2004} & \\
\hline & \multicolumn{2}{|c|}{$\begin{array}{l}\text { Pai da criança era } \\
\text { trabalhador infantil }\end{array}$} & \multicolumn{2}{|c|}{$\begin{array}{l}\text { Mãe da criança era } \\
\text { trabalhadora infantil }\end{array}$} & \\
\hline Criança trabalha & Não & Sim & Não & Sim & Total \\
\hline Não & 8.402 & 15.549 & 15.136 & 8.815 & 23.951 \\
\hline$\underline{\operatorname{Sim}}$ & 316 & 2.237 & 659 & 1.894 & 2.553 \\
\hline Total & 8.718 & 17.786 & 15.795 & 10.709 & 26.504 \\
\hline
\end{tabular}

Fonte: Pnad (1992, 2004) - Elaboração própria. 
atividades laborais antes de completar 15 anos de idade, ou seja, também trabalharam quando crianças, números que não se alteraram entre 1992 e 2004.

Em termos de correlação, pode-se dizer que, entre as crianças provenientes de famílias em que o pai (mãe) foi trabalhador infantil, 12,6\% (17,7\%) são trabalhadores infantis em 2004. Por outro lado, entre as crianças vindas de famílias de pais (mães) que não foram trabalhadores infantis, somente 3,6\% (4,2\%) atuam no mercado de trabalho. Constata-se, portanto, uma relação positiva entre a condição de trabalho infantil dos pais e dos filhos, sendo essa relação ainda mais intensa entre as mães e os filhos. Apesar da maior incidência de trabalho infantil em 1992, esse resultado também é válido para aquele ano.

As tabelas 3 e 4 apresentam dados similares aos anteriores; porém, dado o propósito deste artigo, a análise é subdividida para as regiões urbanas e rurais do Brasil, respectivamente.

As frequências relativas de trabalho infantil são muito diferentes entre as regiões urbana e rural. Em 2004, das crianças de 10 a 14 anos residentes em áreas urbanas, 5,1\% eram trabalhadoras infantis. Esse número chega a ser cinco vezes maior para as crianças que viviam em áreas rurais (25,6\%), apesar de a queda no trabalho infantil ter sido mais pronunciada nas áreas rurais - $62 \%$ contra $49 \%$ nas urbanas.

Tabela 3: Distribuição de trabalho infantil de acordo com o status de trabalhador infantil do pai e da mãe, Brasil Urbano

\begin{tabular}{|c|c|c|c|c|c|}
\hline \multirow[b]{3}{*}{ Criança trabalha } & \multicolumn{4}{|c|}{$\begin{array}{c}\text { Brasil Urbano } \\
1992\end{array}$} & \multirow[b]{3}{*}{ Total } \\
\hline & \multicolumn{2}{|c|}{$\begin{array}{l}\text { Pai da criança era } \\
\text { trabalhador infantil }\end{array}$} & \multicolumn{2}{|c|}{$\begin{array}{l}\text { Mãe da criança era } \\
\text { trabalhadora infantil }\end{array}$} & \\
\hline & Não & Sim & Não & Sim & \\
\hline Não & 7.116 & 12.805 & 14.091 & 5.830 & 19.921 \\
\hline Sim & 450 & 1.861 & 1.098 & 1.213 & 2.311 \\
\hline \multirow[t]{3}{*}{ Total } & 7.566 & 14.666 & 15.189 & 7.043 & 22.232 \\
\hline & \multicolumn{4}{|c|}{2004} & \\
\hline & \multicolumn{2}{|c|}{$\begin{array}{c}\text { Pai da criança era } \\
\text { trabalhadora infantil }\end{array}$} & \multicolumn{2}{|c|}{$\begin{array}{l}\text { Mãe da criança era } \\
\text { trabalhadora infantil }\end{array}$} & \\
\hline Criança trabalha & Não & Sim & Não & Sim & Total \\
\hline Não & 7.703 & 11.882 & 13.313 & 6.272 & 19.585 \\
\hline Sim & 234 & 817 & 429 & 622 & 1.051 \\
\hline Total & 7.937 & 12.699 & 13.742 & 6.894 & 20.636 \\
\hline
\end{tabular}


A correlação entre o fato de o pai ter sido trabalhador infantil e o fato de a criança atualmente ser trabalhadora infantil também é mais marcante na região rural. Na amostra "Brasil Urbano", a probabilidade de trabalhar de crianças cujo pai (mãe) foi trabalhador infantil é de 6,4\% (9\%); já na amostra "Brasil Rural", essa probabilidade é de 28\% (33\%). A mesma relação é encontrada para 1992, demonstrando que a queda do trabalho infantil foi geral, tanto no que diz respeito à região de residência como com relação ao status dos pais como trabalhadores infantis ou não.

Como se esperava, a análise preliminar dos dados revelou a existência de um vínculo entre a probabilidade de a criança trabalhar e o fato de seus pais terem sido trabalhadores infantis. Além disso, essa ligação se mostrou ainda mais forte para as crianças residentes em áreas rurais do Brasil, o que favorece a opção de se realizar análises separadas para as regiões urbana e rural. Vale ressaltar que esses resultados apenas refletem as probabilidades incondicionais. Na seção seguinte são apresentados os resultados da probabilidade condicional de trabalho. A adição de diversas variáveis de controle nos permitirá gerar estimativas mais corretas acerca do impacto intergeracional do trabalho infantil. Por fim, cabe destacar que a queda do trabalho infantil se deu tanto nas áreas rurais como nas urbanas e independente do fato de os pais terem sido ou não trabalhadores infantis.

Tabela 4: Distribuição de trabalho infantil de acordo com o status de trabalhador infantil do pai e da mãe, Brasil Rural

\begin{tabular}{|c|c|c|c|c|c|}
\hline \multicolumn{6}{|c|}{$\begin{array}{c}\text { Brasil Rural } \\
1992\end{array}$} \\
\hline \multirow[b]{2}{*}{ Criança trabalha } & \multicolumn{2}{|c|}{$\begin{array}{l}\text { Pai da criança era } \\
\text { trabalhador infantil }\end{array}$} & \multicolumn{2}{|c|}{$\begin{array}{l}\text { Mãe da criança era } \\
\text { trabalhadora infantil }\end{array}$} & \multirow[b]{2}{*}{ Total } \\
\hline & Não & Sim & Não & Sim & \\
\hline Não & 584 & 3.374 & 1.730 & 2.228 & 3.958 \\
\hline Sim & 200 & 2.552 & 642 & 2.110 & 2.752 \\
\hline Total & 784 & 5.926 & 2.372 & 4.338 & 6.710 \\
\hline \multicolumn{6}{|c|}{2004} \\
\hline & \multicolumn{2}{|c|}{$\begin{array}{l}\text { Pai da criança era } \\
\text { trabalhador infantil }\end{array}$} & \multicolumn{2}{|c|}{$\begin{array}{l}\text { Mãe da criança era } \\
\text { trabalhadora infantil }\end{array}$} & \\
\hline Criança trabalha & Não & Sim & Não & Sim & Total \\
\hline Não & 699 & 3.667 & 1.823 & 2.543 & 4.366 \\
\hline Sim & 82 & 1.420 & 230 & 1.272 & 1.502 \\
\hline Total & 781 & 5.087 & 2.053 & 3.815 & 5.868 \\
\hline
\end{tabular}

Fonte: Pnad (1992, 2004) - Elaboração própria. 


\section{RESULTADOS}

\subsection{Estimação}

A partir dos objetivos do presente trabalho, que são o estudo detalhado da persistência do trabalho infantil nas famílias brasileiras das zonas rural e urbana e a decomposição paramétrica da redução do trabalho infantil entre 1992 e 2004, a investigação empírica a ser apresentada na presente seção baseou-se na estimação de modelos probites em cross-section, tendo como variável dependente uma variável que assume o valor 1 quando a criança trabalhou qualquer quantidade positiva de horas no mercado trabalho e 0 em caso contrário. As regressões são ponderadas pelo variável de peso da Pnad e são robustas à heterocedasticidade.

Inicialmente, estimamos o modelo com os dados conjuntos das zonas urbana e rural, mas testes de razão de verossimilhança para os anos $1992 \mathrm{e}$ 2004, cujos resultados são apresentados na tabela 5, indicaram a necessidade de se estimar separadamente o modelo para áreas rurais e urbanas.

Desse modo, os resultados da estimação dos modelos para as diferentes regiões (urbano e rural) e para os anos de 1992 e 2004 são apresentados na tabela 6. Assim como obtido por Emerson e Souza (2003), o fato de os pais terem sido trabalhadores infantis tem um efeito positivo e significante (a $1 \%$ ) sobre a probabilidade de seus filhos serem trabalhadores infantis em ambos os anos e nas áreas rural e urbana. Entretanto, esse efeito é maior na área rural e tem magnitude menor em 2004, se comparada a 1992, exceto para mãe trabalhadora infantil na área rural. Assim, parece que o intervalo de tempo considerado (12 anos), apesar de relativamente curto, foi suficiente para atenuar o efeito da persistência intergeracional do trabalho infantil. Obviamente, o mercado de trabalho e o arcabouço institucional brasileiro mudaram no período e é bem provável que outros fatores e políticas podem ter atenuado essa persistência, embora não seja nosso objetivo aqui medir o efeito direto dessas políticas.

Tabela 5: Testes de máxima verossimilhança, 1992 e 2004

\begin{tabular}{lll}
\hline 1992 & LR chi2 $(18)=209,53$ & Prob $>$ chi2 $=0,000$ \\
\hline $2004 \quad \operatorname{LR}$ chi2 $(18)=149,91$ & Prob $>$ chi2 $=0,000$ \\
\hline Fonte: Elaboração própria.
\end{tabular}


Tabela 6: Efeitos marginais da probabilidade de ser trabalhador infantil

\begin{tabular}{|c|c|c|c|c|}
\hline & \multicolumn{2}{|c|}{ Rural } & \multicolumn{2}{|c|}{ Urbana } \\
\hline & 1992 & 2004 & 1992 & 2004 \\
\hline \multirow[t]{2}{*}{ Pai trabalhador infantil } & 0,1224 & 0,0837 & 0,0260 & 0,0125 \\
\hline & $(0,0197)$ & $(0,0167)$ & $(0,0036)$ & $(0,0027)$ \\
\hline \multirow[t]{2}{*}{ Mãe trabalhadora infantil } & 0,1597 & 0,1460 & 0,0468 & 0,0213 \\
\hline & $(0,0137)$ & $(0,0125)$ & $(0,0049)$ & $(0,0035)$ \\
\hline \multirow[t]{2}{*}{ Idade da criança } & 0,0889 & 0,0557 & 0,0335 & 0,0169 \\
\hline & $(0,0046)$ & $(0,0041)$ & $(0,0012)$ & $(0,0009)$ \\
\hline \multirow[t]{2}{*}{ Menina } & $-0,3399$ & $-0,2090$ & $-0,0673$ & $-0,0264$ \\
\hline & $(0,0115)$ & $(0,0108)$ & $(0,0034)$ & $(0,0025)$ \\
\hline \multirow[t]{2}{*}{ Idade do pai } & 0,0013 & $-0,0002$ & 0,0006 & 0,0005 \\
\hline & $(0,0010)$ & $(0,0009)$ & $(0,0002)$ & $(0,0002)$ \\
\hline \multirow[t]{2}{*}{ Idade da mãe } & 0,0012 & 0,0025 & $-0,0004$ & $-0,0001$ \\
\hline & $(0,0012)$ & $(0,0010)$ & $(0,0003)$ & $(0,0002)$ \\
\hline \multirow[t]{2}{*}{ Pai fora do mercado } & $-0,1954$ & $-0,0565$ & $-0,0228$ & $-0,0088$ \\
\hline & $(0,0236)$ & $(0,0230)$ & $(0,0046)$ & $(0,0034)$ \\
\hline \multirow[t]{2}{*}{ Mãe fora do mercado } & $-0,2089$ & $-0,1517$ & $-0,0297$ & $-0,0230$ \\
\hline & $(0,0132)$ & $(0,0122)$ & $(0,0042)$ & $(0,0030)$ \\
\hline \multirow[t]{2}{*}{ Escolaridade do pai } & $-0,0136$ & $-0,0078$ & $-0,0049$ & $-0,0018$ \\
\hline & $(0,0032)$ & $(0,0025)$ & $(0,0006)$ & $(0,0004)$ \\
\hline \multirow[t]{2}{*}{ Escolaridade da mãe } & $-0,0032$ & $-0,0102$ & $-0,0053$ & $-0,0021$ \\
\hline & $(0,0031)$ & $(0,0023)$ & $(0,0006)$ & $(0,0004)$ \\
\hline \multirow[t]{2}{*}{$N^{\circ}$ de irmãs 0-5 anos } & 0,0293 & 0,0189 & 0,0141 & 0,0081 \\
\hline & $(0,0107)$ & $(0,0114)$ & $(0,0034)$ & $(0,0031)$ \\
\hline \multirow[t]{2}{*}{$N^{\circ}$ de irmãs 6-9 anos } & 0,0452 & 0,0117 & 0,0072 & 0,0097 \\
\hline & $(0,0102)$ & $(0,0104)$ & $(0,0031)$ & $(0,0025)$ \\
\hline \multirow[t]{2}{*}{$\mathrm{N}^{\circ}$ de irmãs 10-14 anos } & 0,0022 & $-0,0005$ & 0,0077 & 0,0040 \\
\hline & $(0,0099)$ & $(0,0099)$ & $(0,0028)$ & $(0,0024)$ \\
\hline \multirow[t]{2}{*}{$\mathrm{N}^{\circ}$ de irmãs $15-17$ anos } & 0,0152 & 0,0206 & 0,0026 & 0,0017 \\
\hline & $(0,0124)$ & $(0,0124)$ & $(0,0035)$ & $(0,0030)$ \\
\hline \multirow[t]{2}{*}{$\mathrm{N}^{\circ}$ de irmãos 0-5 anos } & 0,0479 & 0,0174 & 0,0148 & 0,0045 \\
\hline & $(0,0105)$ & $(0,0116)$ & $(0,0034)$ & $(0,0030)$ \\
\hline \multirow[t]{2}{*}{$\mathrm{N}^{\circ}$ de irmãos 6-9 anos } & 0,0397 & 0,0397 & 0,0153 & 0,0019 \\
\hline & $(0,0105)$ & $(0,0106)$ & $(0,0031)$ & $(0,0026)$ \\
\hline \multirow[t]{2}{*}{$\mathrm{N}^{\circ}$ de irmãos $10-14$ anos } & 0,0000 & $-0,0117$ & 0,0058 & 0,0040 \\
\hline & $(0,0095)$ & $(0,0096)$ & $(0,0027)$ & $(0,0024)$ \\
\hline \multirow[t]{2}{*}{$\mathrm{N}^{\circ}$ de irmãos 15-17 anos } & $-0,0112$ & 0,0323 & 0,0023 & $-0,0017$ \\
\hline & $(0,0118)$ & $(0,0108)$ & $(0,0033)$ & $(0,0028)$ \\
\hline Chi2(n) & $1.527,26$ & 940,1 & $1.891,13$ & 837,1 \\
\hline Prob > Chi2 & 0,0000 & 0,0000 & 0,0000 & 0,0000 \\
\hline Pseudo R2 & 0,1952 & 0,1806 & 0,1603 & 0,1341 \\
\hline $\mathrm{N}^{\circ}$ de observações & 7.154 & 5.868 & 21.516 & 20.636 \\
\hline
\end{tabular}

Desvios-padrão robustos entre parênteses.

Fonte: Pnad (1992, 2004) - Elaboração própria. 
Portanto, de acordo com os resultados, parece existir um impacto intergeracional do trabalho infantil. Vale ressaltar que Emerson e Souza (2003) afirmam que, se esse fenômeno fosse exclusivamente explicado pela "armadilha" intergeracional comentada na seção relativa ao referencial teórico, bastaria a inserção de uma variável proxy adequada para representar a riqueza das famílias, o que resultaria na eliminação dos efeitos do status de trabalhador infantil dos pais sobre a probabilidade de seus filhos ofertarem trabalho. Assim, a inclusão no modelo da variável de escolaridade dos pais foi justamente para tentar investigar esse ponto. No entanto, apesar de a escolaridade dos pais afetar negativamente a possibilidade de as crianças trabalharem, sua exclusão não altera o impacto da variável de interesse. $\mathrm{Ou}$ seja, o coeficiente associado à variável que capta o status de trabalhador infantil dos pais continua positivo e significante, o que evidencia a existência de um possível mecanismo de transmissão do trabalho infantil entre as gerações que vai além da explicação conferida pelo círculo vicioso da pobreza e/ou trabalho infantil.

Por sua vez, os efeitos das demais variáveis sobre a probabilidade de a criança ofertar trabalho no mercado apresentam resultados qualitativamente similares aos obtidos por Emerson e Souza (2003) para as famílias brasileiras no ano 1996, embora as magnitudes sejam diferentes dependendo da combinação ano/região. Crianças do sexo feminino e que têm pais (pai e mãe) que não fazem parte do mercado de trabalho apresentam menor possibilidade de trabalhar. Vale dizer que esses efeitos são maiores nas áreas rurais do que nas urbanas. Por outro lado, quanto maior o número de irmãos e/ou irmãs menores de 10 anos, maior a probabilidade de a criança trabalhar. Provavelmente, um maior número de irmãos pequenos deve aumentar a importância da renda obtida com o trabalho das crianças maiores de 10 anos, que são nosso universo de análise.

Assim, de forma geral, a comparação entre os efeitos marginais das áreas urbana e rural sobre a probabilidade de a criança ser trabalhadora infantil mostra que as principais variáveis (pais trabalhadores infantis, escolaridade dos pais, idade da criança, sexo, participação dos pais no mercado de trabalho) apresentam o mesmo sinal independentemente da região onde elas habitam. Além disso, a análise também permite corroborar a existência do fenômeno da persistência do trabalho infantil nas quatro especificações. 
Na tabela A1 do Apêndice, apresentamos os resultados da estimação acrescentando como variável explicativa a renda familiar líquida, definida como sendo a renda familiar deduzida do rendimento da criança. Tal como ressaltado por Emerson e Souza (2003), a inclusão dessa variável, apesar de introduzir problemas de endogeneidade, é de grande valia por permitir o teste do grau de adequação das variáveis de escolaridade dos pais como proxies para a riqueza familiar. Caso as variáveis indicadoras da riqueza das famílias nos modelos anteriormente especificados não fossem representativas desta, a inclusão da renda familiar poderia captar uma parte dos efeitos da "armadilha" intergeracional sobre o trabalho infantil. Dessa forma, isso minoraria a relevância da influência do status passado dos pais sobre a probabilidade de as crianças serem trabalhadoras infantis.

A partir da observação dos efeitos marginais obtidos após a inclusão da variável renda familiar líquida no modelo, percebe-se que esta apresenta um efeito muito pequeno (urbano) e não significativo (rural), além de não promover alterações relevantes nos sinais e magnitudes das variáveis que captam a persistência do trabalho infantil e da riqueza das famílias tanto para a realidade do ambiente rural quanto urbano.

\subsection{Decomposição}

Passamos a apresentar agora os resultados da decomposição da variação do trabalho infantil entre 1992 e 2004. É feita uma decomposição para a área rural e outra para a urbana. O primeiro ponto a ser destacado é que houve uma queda muito mais pronunciada do trabalho infantil rural do que do urbano no período. A tabela 7 apresenta os resultados. Inicialmente, constata-se que a mudança nos valores dos regressores explica $21 \%$ da redução da incidência do trabalho infantil na área urbana e 7,9\% na área rural. Ou seja, a mudança nas características inerentes aos indivíduos da amostra entre 1992 e 2004 explica a menor parte da redução do trabalho infantil. Entretanto, destaca-se a melhoria do nível educacional dos pais e mães na área rural (9,3\%), embora a maior proporção de mães trabalhando na área rural tenha contrabalançado esse efeito $(-6,9 \%)$. Os resultados com relação à variação dos valores dos regressores para a área urbana são semelhantes. 
Tabela 7: Decomposição da variação do trabalho infantil entre 1992 e 2004

\begin{tabular}{|c|c|c|c|c|c|c|}
\hline \multirow[t]{2}{*}{ Regressores } & \multicolumn{2}{|c|}{ Variáveis } & \multicolumn{2}{|c|}{ Oaxaca-Blinder } & \multicolumn{2}{|c|}{ Yun } \\
\hline & & $\begin{array}{l}\Delta \text { trab. } \\
\text { infantil }\end{array}$ & Coeficientes & $\begin{array}{l}\Delta \text { trab. } \\
\text { infantil }\end{array}$ & Coeficientes & $\begin{array}{l}\Delta \text { trab. } \\
\text { infantil }\end{array}$ \\
\hline \multicolumn{7}{|l|}{ Rural } \\
\hline Pai trab. infantil & $-0,0012$ & $0,8 \%$ & $-0,00513$ & $3,3 \%$ & $-0,0022$ & $1,4 \%$ \\
\hline Mãe trab. infantil & 0,0008 & $-0,5 \%$ & 0,02370 & $-15,0 \%$ & 0,0054 & $-3,4 \%$ \\
\hline Escolaridade pai & $-0,0061$ & $3,9 \%$ & 0,00266 & $-1,7 \%$ & 0,0027 & $-1,7 \%$ \\
\hline Escolaridade mãe & $-0,0086$ & $5,4 \%$ & $-0,01440$ & $9,1 \%$ & $-0,0144$ & $9,1 \%$ \\
\hline Idade criança & 0,0023 & $-1,5 \%$ & $-0,13374$ & $84,9 \%$ & $-0,1337$ & $84,9 \%$ \\
\hline Sexo criança & 0,0006 & $-0,4 \%$ & 0,02815 & $-17,9 \%$ & $-0,0012$ & $0,7 \%$ \\
\hline Emprego do pai & $-0,0005$ & $0,3 \%$ & 0,00587 & $-3,7 \%$ & $-0,0440$ & $27,9 \%$ \\
\hline Emprego da mãe & 0,0109 & $-6,9 \%$ & 0,00076 & $-0,5 \%$ & 0,0000 & $0,0 \%$ \\
\hline Idade pai & 0,0001 & $-0,1 \%$ & $-0,05603$ & $35,6 \%$ & $-0,0560$ & $35,6 \%$ \\
\hline Idade mãe & $-0,0018$ & $1,2 \%$ & 0,07289 & $-46,3 \%$ & 0,0729 & $-46,3 \%$ \\
\hline $\mathrm{N}^{\circ}$ irmãs 0-5 & $-0,0012$ & $0,8 \%$ & $-0,00360$ & $2,3 \%$ & $-0,0036$ & $2,3 \%$ \\
\hline $\mathrm{N}^{\circ}$ irmãs 6-9 & $-0,0013$ & $0,8 \%$ & $-0,00835$ & $5,3 \%$ & $-0,0083$ & $5,3 \%$ \\
\hline № irmãs 10-14 & 0,0001 & $0,0 \%$ & $-0,00072$ & $0,5 \%$ & $-0,0007$ & $0,5 \%$ \\
\hline $\mathrm{N}^{\circ}$ irmãs 15-17 & $-0,0011$ & $0,7 \%$ & 0,00254 & $-1,6 \%$ & 0,0025 & $-1,6 \%$ \\
\hline $\mathrm{N}^{\circ}$ irmãos 0-5 & $-0,0014$ & $0,9 \%$ & $-0,00844$ & $5,4 \%$ & $-0,0084$ & $5,4 \%$ \\
\hline No irmãos 6-9 & $-0,0037$ & $2,4 \%$ & 0,00499 & $-3,2 \%$ & 0,0050 & $-3,2 \%$ \\
\hline $\mathrm{N}^{\circ}$ irmãos 10-14 & 0,0011 & $-0,7 \%$ & $-0,00503$ & $3,2 \%$ & $-0,0050$ & $3,2 \%$ \\
\hline $\mathrm{N}^{\circ}$ irmãos 15-17 & $-0,0015$ & $0,9 \%$ & 0,01234 & $-7,8 \%$ & 0,0123 & $-7,8 \%$ \\
\hline Constante & 0,0000 & $0,0 \%$ & $-0,06343$ & $40,3 \%$ & 0,0319 & $-20,3 \%$ \\
\hline Total & $-0,0125$ & $7,9 \%$ & $-0,14499$ & $92,1 \%$ & $-0,1450$ & $92,1 \%$ \\
\hline \multicolumn{7}{|l|}{ Urbano } \\
\hline Pai trab. infantil & $-0,0008$ & $1,5 \%$ & $-0,0045$ & $8,3 \%$ & $-0,0011$ & $2,0 \%$ \\
\hline Mãe trab. infantil & 0,0005 & $-1,0 \%$ & $-0,0028$ & $5,2 \%$ & 0,0016 & $-3,0 \%$ \\
\hline Escolaridade pai & $-0,0038$ & $7,1 \%$ & 0,0079 & $-14,6 \%$ & 0,0079 & $-14,6 \%$ \\
\hline Escolaridade mãe & $-0,0056$ & $10,3 \%$ & 0,0083 & $-15,3 \%$ & 0,0083 & $-15,3 \%$ \\
\hline Idade criança & 0,0005 & $-1,0 \%$ & $-0,0270$ & $49,7 \%$ & $-0,0270$ & $49,7 \%$ \\
\hline Sexo criança & $-0,0002$ & $0,4 \%$ & 0,0110 & $-20,2 \%$ & $-0,0002$ & $0,3 \%$ \\
\hline Emprego do pai & $-0,0002$ & $0,3 \%$ & 0,0009 & $-1,7 \%$ & $-0,0028$ & $5,1 \%$ \\
\hline Emprego da mãe & 0,0030 & $-5,6 \%$ & $-0,0091$ & $16,7 \%$ & $-0,0007$ & $1,3 \%$ \\
\hline Idade pai & $-0,0004$ & $0,7 \%$ & 0,0094 & $-17,3 \%$ & 0,0094 & $-17,3 \%$ \\
\hline Idade mãe & 0,0000 & $-0,1 \%$ & 0,0110 & $-20,3 \%$ & 0,0110 & $-20,3 \%$ \\
\hline $\mathrm{N}^{\circ}$ irmãs $0-5$ & $-0,0008$ & $1,4 \%$ & 0,0005 & $-0,9 \%$ & 0,0005 & $-0,9 \%$ \\
\hline № irmãs 6- 9 & $-0,0013$ & $2,4 \%$ & 0,0044 & $-8,1 \%$ & 0,0044 & $-8,1 \%$ \\
\hline № irmãs 10-14 & $-0,0009$ & $1,7 \%$ & 0,0005 & $-0,9 \%$ & 0,0005 & $-0,9 \%$ \\
\hline $\mathrm{N}^{\circ}$ irmãs 15-17 & $-0,0002$ & $0,3 \%$ & 0,0003 & $-0,6 \%$ & 0,0003 & $-0,6 \%$ \\
\hline $\mathrm{N}^{\circ}$ irmãos 0-5 & $-0,0003$ & $0,6 \%$ & $-0,0016$ & $3,0 \%$ & $-0,0016$ & $3,0 \%$ \\
\hline № irmãos 6-9 & $-0,0002$ & $0,4 \%$ & $-0,0043$ & $7,8 \%$ & $-0,0043$ & $7,8 \%$ \\
\hline $\mathrm{N}^{\circ}$ irmãos 10-14 & $-0,0010$ & $1,8 \%$ & 0,0014 & $-2,6 \%$ & 0,0014 & $-2,6 \%$ \\
\hline № irmãos 15-17 & 0,0001 & $-0,2 \%$ & $-0,0011$ & $2,0 \%$ & $-0,0011$ & $2,0 \%$ \\
\hline Constante & 0,0000 & $0,0 \%$ & $-0,0480$ & $88,5 \%$ & $-0,0495$ & $91,1 \%$ \\
\hline Total & $-0,0115$ & $21,1 \%$ & $-0,0428$ & $78,9 \%$ & $-0,0428$ & $78,9 \%$ \\
\hline
\end{tabular}

Obs: $\Delta$ trab. infantil rural $=-15.74$ p.p. $\Delta$ trab. infantil urbano $=-5.43$ p.p. 
A melhoria na escolaridade média dos pais (mães), representada por um aumento de 3,5 $(3,6)$ para 4,5 $(4,9)$ anos de estudo, provavelmente fez com que estes passassem a entender melhor o valor da educação de seus filhos e seus respectivos retornos futuros. Assim, aumentam-se os incentivos à educação dos filhos e, dada a disputa de tempo entre escola e mercado de trabalho, reduz-se a disponibilidade da criança para o trabalho. Quanto ao fato de as mães estarem, em média, trabalhando mais, isso faz com que elas permaneçam menos tempo em casa com os seus filhos. A partir daí, reduz-se o tempo disponível tanto para o acompanhamento como para as cobranças e incentivos acerca do desempenho escolar dessas crianças. Por essa razão, pode ser que as crianças se sintam menos motivadas aos estudos, e como alternativa, tenderiam a entrar precocemente no mercado de trabalho.

No que diz respeito à contribuição da alteração dos coeficientes das estimações para a queda no trabalho infantil, fica clara a importância de se adotar a metodologia de Yun, pois os resultados diferem dos da metodologia de Oaxaca-Blinder padrão. Assim, por exemplo, enquanto a redução do coeficiente associado ao fato de a mãe ter sido trabalhadora infantil contribuiria para aumentar a incidência de trabalho infantil em 2,37 p.p., entre 1992 e 2004, na área rural na decomposição de Oaxaca-Blinder, na de Yun esse número seria de apenas 0,54 p.p. Isso também é válido para o coeficiente associado ao sexo da criança na área rural. Desse modo, iremos concentrar nossa análise da decomposição de Yun no que tange à contribuição dos coeficientes para redução do trabalho infantil.

O primeiro ponto a ser destacado é que existem diferenças consideráveis nas decomposições para o setor urbano e para o rural. A alteração dos coeficientes da escolaridade do pai e da mãe na área urbana contribuiria no sentido de elevar o trabalho infantil em 0,79 p.p. e 0,83 p.p., respectivamente. Já nas áreas rurais esses valores seriam, respectivamente, 0,03 p.p. e-1,44 p.p. Por sua vez, a maior contribuição para a redução do trabalho infantil vem da alteração dos coeficientes relativos à idade da criança. Na área urbana, mas principalmente na área rural, a pronunciada diminuição dos efeitos marginais da idade sobre a incidência do trabalho infantil entre 1992 e 2004 faz com que esse fator responda por pelo menos metade da redução da incidência do trabalho infantil. 
Uma possível justificativa para essa queda na predisposição da criança para o trabalho seriam alterações institucionais ou de políticas públicas, tais como programas de redução do trabalho infantil e/ou de incentivo à presença da criança na escola, de forma a reduzir o tempo disponível para o trabalho infantil. E esta redução não estaria relacionada diretamente com as características de background familiar, como escolaridade, condição de trabalho infantil dos pais, região de residência, entre outras variáveis utilizadas como controles nos exercícios.

Por fim, cabe destacar o papel da idade dos pais. Enquanto nas áreas urbanas a alteração dos coeficientes contribuiu para aumentar o trabalho infantil, nas áreas rurais isso só foi verdade para as mães.

\section{CONSIDERAÇÕES FINAIS}

O presente artigo procurou avaliar duas questões relacionadas ao trabalho infantil. Inicialmente, identificar a persistência intergeracional do trabalho infantil, analisando isoladamente as áreas rurais e urbanas do Brasil. Assim como obtido por Emerson e Souza (2003), os resultados mostraram que o fato de os pais terem sido trabalhadores infantis teve um efeito positivo e significante sobre a probabilidade de seus filhos serem trabalhadores infantis.

Ao incluir a escolaridade dos pais como proxy da riqueza das famílias, notou-se que essa variável afetou negativamente a probabilidade de as crianças trabalharem; todavia, o efeito do status de trabalho infantil dos pais (pai e mãe) continuou positivo e significante, trazendo evidências da existência de um possível mecanismo de transmissão do trabalho infantil entre as gerações que vai além da explicação conferida pelo círculo vicioso da pobreza e/ou trabalho infantil.

A análise isolada das regiões rurais e urbanas, decisão corroborada pelo teste de razão de verossimilhança, mostrou que, apesar de fortes diferenças em termos de escala, as principais variáveis (pais trabalhadores infantis, escolaridade dos pais, idade da criança, sexo, participação dos pais no mercado de trabalho) apresentaram o mesmo sinal independentemente da região analisada. Constatou-se, mais uma vez, a existência de ligações fortes entre 
a condição de trabalho infantil dos pais e seus filhos. Todavia, a magnitude desse impacto foi muito mais acentuada na zona rural comparativamente à área urbana.

O segundo objetivo do trabalho foi decompor a evolução da incidência do trabalho infantil entre 1992 e 2004, procurando identificar as principais causas da sua redução. Analisando separadamente as áreas urbanas e rurais, conclui-se que a mudança nos valores dos atributos determinantes do trabalho infantil responde por no máximo $21 \%$ da redução experimentada no período, com destaque para a maior escolaridade dos pais e mães como indutora da redução do trabalho infantil. Por outro lado, o retorno a essas mesmas características contribuiu para atenuar a redução.

Por fim, pode-se argumentar que as grandes diferenças quanto à probabilidade de ser trabalhador infantil entre as regiões urbana e rural, possivelmente têm inúmeras e distintas explicações. Por exemplo, na zona rural as meninas tendem a ter uma menor participação no mercado de trabalho relativamente aos garotos, já que ficam mais atreladas às atividades domésticas das residências, ou mesmo porque o trabalho rural, em geral, tem como característica a maior exigência de força física, o que inviabiliza uma maior demanda por trabalho de crianças do sexo feminino. Vale ainda ressaltar que o trabalho infantil na produção familiar pode ter um caráter positivo, em termos de socialização da criança. Isso porque o trabalho pode estar associado a um processo de aprendizado, embora seja provável que o trabalho infantil seja mais justificado por esse tipo de argumento do que realmente traga efeitos benéficos.

Essas distinções entre os efeitos nas áreas rural e urbana evidenciam a necessidade de uma maior atenção dos estudos teóricos e empíricos sobre as diferenças de contexto entre essas duas realidades que provavelmente têm determinantes diferentes, sendo também diferenciado o papel da persistência do trabalho infantil. Dessa forma cabe ressaltar que políticas públicas que objetivam eliminar ou reduzir a incidência do trabalho infantil no país devem incorporar essas características intrínsecas do problema em cada região socioeconômica para obter uma maior efetividade de suas ações, dando maior ênfase para as áreas rurais brasileiras, em que a incidência desse tipo de trabalho é maior, assim como sua persistência intergeracional. 


\section{Apêndice}

\begin{tabular}{|c|c|c|c|c|}
\hline & \multicolumn{2}{|c|}{ Rural } & \multicolumn{2}{|c|}{ Urbana } \\
\hline & 1992 & 2004 & 1992 & 2004 \\
\hline \multirow[t]{2}{*}{ Pai trabalhador infantil } & 0,1287 & 0,0832 & 0,0253 & 0,0124 \\
\hline & $(0,0203)$ & $(0,0167)$ & $(0,0036)$ & $(0,0027)$ \\
\hline \multirow[t]{2}{*}{ Mãe trabalhadora infantil } & 0,1617 & 0,1450 & 0,0462 & 0,0208 \\
\hline & $(0,0141)$ & $(0,0126)$ & $(0,0049)$ & $(0,0035)$ \\
\hline \multirow[t]{2}{*}{ Idade da criança } & 0,0898 & 0,0558 & 0,0331 & 0,0168 \\
\hline & $(0,0048)$ & $(0,0041)$ & $(0,0012)$ & $(0,0009)$ \\
\hline \multirow[t]{2}{*}{ Menina } & $-0,3399$ & $-0,2088$ & $-0,0655$ & $-0,0263$ \\
\hline & $(0,0119)$ & $(0,0108)$ & $(0,0034)$ & $(0,0025)$ \\
\hline \multirow[t]{2}{*}{ Renda familiar líquida } & 0,0000 & $-1,6$ e -05 & 0,0000 & $-3,0$ e -06 \\
\hline & $(0,000)$ & $(1,0$ e -05$)$ & $(0,000)$ & $(1,2$ e -07$)$ \\
\hline \multirow[t]{2}{*}{ Idade do pai } & 0,0014 & $-0,0001$ & 0,0005 & 0,0005 \\
\hline & $(0,0010)$ & $(0,0009)$ & $(0,0002)$ & $(0,0002)$ \\
\hline \multirow[t]{2}{*}{ Idade da mãe } & 0,0017 & 0,0026 & $-0,0003$ & $-0,0001$ \\
\hline & $(0,0012)$ & $(0,0010)$ & $(0,0003)$ & $(0,0002)$ \\
\hline \multirow[t]{2}{*}{ Pai desempregado } & $-0,1964$ & $-0,0585$ & $-0,0218$ & $-0,0095$ \\
\hline & $(0,0236)$ & $(0,0229)$ & $(0,0046)$ & $(0,0034)$ \\
\hline \multirow[t]{2}{*}{ Mãe desempregada } & $-0,2066$ & $-0,1529$ & $-0,0275$ & $-0,0236$ \\
\hline & $(0,0137)$ & $(0,0122)$ & $(0,0042)$ & $(0,0030)$ \\
\hline \multirow[t]{2}{*}{ Escolaridade do pai } & $-0,0103$ & $-0,0070$ & $-0,0045$ & $-0,0015$ \\
\hline & $(0,0034)$ & $(0,0025)$ & $(0,0006)$ & $(0,0004)$ \\
\hline \multirow[t]{2}{*}{ Escolaridade da mãe } & $-0,0029$ & $-0,0094$ & $-0,0049$ & $-0,0018$ \\
\hline & $(0,0033)$ & $(0,0024)$ & $(0,0006)$ & $(0,0004)$ \\
\hline \multirow[t]{2}{*}{$\mathrm{N}^{\circ}$ de irmãs 0-5 anos } & 0,0283 & 0,0184 & 0,0124 & 0,0080 \\
\hline & $(0,0113)$ & $(0,0114)$ & $(0,0034)$ & $(0,0031)$ \\
\hline \multirow[t]{2}{*}{ 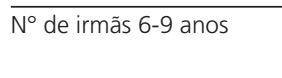 } & 0,0361 & 0,0112 & 0,0078 & 0,0095 \\
\hline & $(0,0107)$ & $(0,0104)$ & $(0,0031)$ & $(0,0025)$ \\
\hline \multirow[t]{2}{*}{$\overline{\mathrm{N}^{\circ} \text { de irmãs } 10-14 \text { anos }}$} & $-0,0071$ & $-0,0012$ & 0,0083 & 0,0037 \\
\hline & $(0,0103)$ & $(0,0099)$ & $(0,0028)$ & $(0,0024)$ \\
\hline \multirow[t]{2}{*}{$\mathrm{N}^{\circ}$ de irmãs 15-17 anos } & 0,0238 & 0,0205 & 0,0031 & 0,0018 \\
\hline & $(0,0128)$ & $(0,0124)$ & $(0,0035)$ & $(0,0030)$ \\
\hline \multirow[t]{2}{*}{$\overline{\mathrm{N}^{\circ} \text { de irmãos 0-5 anos }}$} & 0,0491 & 0,0173 & 0,0139 & 0,0045 \\
\hline & $(0,0109)$ & $(0,0115)$ & $(0,0034)$ & $(0,0029)$ \\
\hline \multirow[t]{2}{*}{$\mathrm{N}^{\circ}$ de irmãos 6-9 anos } & 0,0383 & 0,0390 & 0,0152 & 0,0019 \\
\hline & $(0,0110)$ & $(0,0106)$ & $(0,0031)$ & $(0,0026)$ \\
\hline \multirow[t]{2}{*}{$\mathrm{N}^{\circ}$ de irmãos 10-14 anos } & $-0,0009$ & $-0,0124$ & 0,0065 & 0,0039 \\
\hline & $(0,0099)$ & $(0,0096)$ & $(0,0027)$ & $(0,0024)$ \\
\hline \multirow[t]{2}{*}{$\mathrm{N}^{\circ}$ de irmãos $15-17$ anos } & $-0,0028$ & 0,0327 & 0,0033 & $-0,0016$ \\
\hline & $(0,0122)$ & $(0,0108)$ & $(0,0033)$ & $(0,0027)$ \\
\hline Chi2(n) & $1.414,84$ & 944,3 & $1.800,08$ & 856,0 \\
\hline Prob > Chi2 & 0,0000 & 0,0000 & 0,0000 & 0,0000 \\
\hline Pseudo R2 & 0,1995 & 0,1810 & 0,1588 & 0,1350 \\
\hline $\mathrm{N}^{\circ}$ de observações & 6.603 & 5.868 & 21.004 & 0.636 \\
\hline
\end{tabular}

Desvios-padrão robustos entre parênteses.

Fonte: Pnad (1992) - Elaboração própria. 


\section{NOTAS}

1. Para mais detalhes sobre a técnica, ver Yun (2005).

2. De acordo com a metodologia da Pnad, a classificação do domicílio em urbano ou rural tem por base a legislação vigente por ocasião da realização do último Censo Demográfico. São consideradas áreas urbanas aquelas correspondentes às cidades (sedes municipais), às vilas (sedes distritais) ou às áreas urbanas isoladas. A situação rural abrange toda a área situada fora desses limites, ou seja, as áreas urbanas são sempre maiores a cada censo. Del Grossi e Graziano da Silva (2002) enfatizam a superestimação da população rural brasileira, já que a definição das áreas censitárias da Pnad é mantida fixa durante uma década, mesmo que essa área passe a ser considerada urbana pela legislação municipal.

3. É importante ressaltar que cerca de $95 \%$ das famílias em nossa amostra não possuem crianças na condição de "outro parente", o que relativiza a importância dessa relação assimétrica com relação aos filhos biológicos.

4. Desse modo, estamos ignorando a possível existência de um viés de seleção amostral das crianças trabalhadoras, o que pode estar introduzindo viés na estimação do nosso modelo. Para mais detalhes sobre essa questão, ver Heckman (1979).

5. A Pnad apresenta essa informação quanto à idade que começou a trabalhar apenas para aquelas pessoas que estavam trabalhando no ano de referência da pesquisa. Assim, o fato de estarmos considerando essa variável pode estar introduzindo seletividade amostral e contribuindo para enviesar os estimadores.

6. Como colocado anteriormente, a pergunta referente à idade que começou a trabalhar é feita apenas para aquelas pessoas que trabalharam no ano de referência da pesquisa. Já a informação sobre a condição de trabalho se refere à semana de referência. Por essa razão, é possível observar pais fora do mercado de trabalho na semana de referência, mas que foram questionados pela Pnad acerca da idade em que começaram a trabalhar por terem trabalhado em algum período durante o ano de referência.

\section{REFERÊNCIAS BIBLIOGRÁFICAS}

BARROS, R. P.; MENDONÇA, R.S.P.; VELAZCO, T. A pobreza é a principal causa do trabalho infantil no Brasil urbano? Rio de Janeiro: Ipea, 1994. 26 p.

CAVALIERI, C. H. Trabalho Infantil e Desempenho Escolar. Anais do XXVIII ENCONTRO NACIONAL DE ECONOMIA - Anpec. Campinas, 2000.

DEL GROSSI, M. E.; GRAZIANO DA SILVA, J. O uso das Pnads para as áreas rurais. Rio de Janeiro: Ipea, 2002. $38 \mathrm{p}$.

EMERSON, P.; SOUZA, A. P. From Childhood to Adulthood: the effects of child labor activities on adult earnings in Brazil. USP: 2002. Disponível em: http://www.arts.cornell.edu econ/75devconf/papers/Souza.pdf. Acesso em 9 set. 2004.

Is there a child labor trap? Inter-generational persistense of child labor in Brazil. Economic Development and Cultural Change, v. 51, p. 375-398, 2003. 
FERRO, A. R. Avaliação do impacto dos programas de Bolsa Escola no Trabalho Infantil no Brasil. 2003. 106f. Dissertação (Mestrado em Economia) - Escola Superior de Agricultura Luiz de Queiroz, Universidade de São Paulo, Piracicaba, 2003.

HECKMAN, J. Sample selection bias as a specification error. Econometrica, v. 47, p. 153-161, 1979.

INTERNATIONAL, LABOR ORGANIZATION. Estatísticas de Crianças Trabalhadoras e Trabalho Infantil de Risco: 1998. Disponível em: http://www.ilo.org.public/portugue/bureau/child/ childhaz.htm. Acesso em: 5 set. 2004.

KASSOUF, A L. O trabalho infantil no Brasil. São Paulo, 1999. 110 p. (Tese de Livre Docência). Deas-Esalq-USP, Piracicaba, 1999.

Trabalho infantil. In: LISBOA, M.; MENEZES-FILHO, N. A. Microeconomia e Sociedade no Brasil. Rio de Janeiro: FGV, 2001.

PNAD. Pesquisa Nacional por Amostra de Domicilios. Rio de Janeiro: IBGE, 2004.

PSACHAROPOULOS, G. Child Labor versus educational attainment. Some Evidence from Latin America. Journal of Population Economics, v. 10, n. 4, p. 377-386, 1997.

ROMER, D. Advanced Macroeconomics. 3. ed. [S.l.]: McGraw-Hill, 2006.

SCHWARTZMAN, F. F.; SCHWARTZMAN, S. F. O Trabalho Infantil no Brasil. UFRJ: 2002. Disponível em: http://www.schwartzman.org.br/simon/trab_inf2004.pdf. Acesso em 11 set. 2004.

SOARES, S.; PIANTO, D. Use of Survey Design for the Evaluation of Social Programs: the Pnad and the program for the eradication of child labor in Brazil. [S.l.: s.n.], 2003.

YUN, M. Normalizad Equation and Decomposition Analysis: computation and inference. IZA Discussion Paper, Institute for the Study of Labor, n. 1822, 2005. 